\title{
Body Mass Index and Other Factors Related to Mastalgia: A Cross Sectional Study
}

\author{
Rehab Sabry $^{1 *}$ (D), Tamer M. Kolib², Marwa Ahmed ${ }^{1}$ D, Heba G. Elnahas ${ }^{1}$ \\ ${ }^{1}$ Department of Family Medicine, Faculty of Medicine, Cairo University, Cairo, Egypt; ${ }^{2}$ Consultant of Family Medicine, Primary \\ Health Care Corporation, Doha, Qatar
}

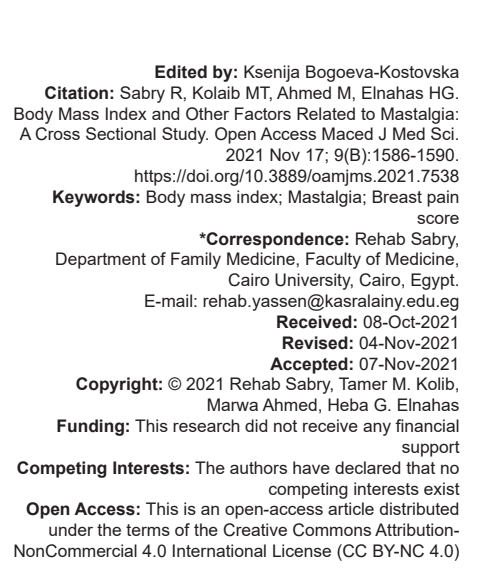

Introduction

Mastalgia is pain that occurs in the tissue of the breast. Mastalgia during the fertile phase is known to be the most common benign breast condition in females. In women aged $30-50$ years, it is most prevalent. Around $70 \%$ of females feel it throughout their lives. During the premenstrual cycle, mild breast pain is a common occurrence $(45 \%)$; however, about $25 \%$ of women report moderate to extreme pain for five or more days during each menstrual cycle [1].

Cyclical and non-cyclical are two predominant forms of mastalgia, depending on its relation with the menstrual cycle. The most common form is cyclical mastalgia, which occurs in the luteal phase of the menstrual cycle. Symptoms include breast pain, tenderness, and heaviness [2].

Mastalgia is variable in degrees of severity, it may cause some degree of pain or anxiety in some patients that need frequent investigations to be done and in the other category [3].

Theories about the pathophysiology of mastalgia are increased estrogen, increased prolactin, reduced progesterone levels, or changes in the estrogen/progesterone ratio. Breast pain is associated with menstrual disorders, oral contraceptives, hormone therapy, psychotropic medications, psychosocial causes, and emotional stress [4]. The quality of life of women may be adversely affected by extreme mastalgia [5].

The most significant initial workups for mastalgia are reassurance and workups that exclude cancer. Medical care in the form of analgesics that could be used locally or systemically has been studied and has been shown to be beneficial in mild to moderate mastalgia. Hormonal therapies are also used in cases of serious mastalgia and failure of first-line therapy [6].

The purpose of the present study was to investigate the factors affecting mastalgia.

\section{Methodology}

This is an analytical cross-sectional study. It conducted on 148 females attending the Family 
Medicine outpatient clinic at Cairo university and Cancer Prevention and Early Detection unit of National Cancer Institute from October 2019 toApril 2020. Premenopausal females, aged 18-55 years old, experiencing cyclic mastalgia (bilateral breast pain defined as heaviness or dullness lasting for at least 3 months approximately 1 week/month around the menstrual cycle) were invited to participate in the study. The exclusion criteria include pregnant and lactating females, those with a recent history of breast abscess of inflammation, those with a history of cancer breast or breast surgery, females who use medications that can influence the pain score, such as (Non-steroidal anti-inflammatory drugs, analgesics, aspirin, acetaminophen).

\section{Sample size}

Based on the previous study in Egypt where the recorded prevalence of mastalgia in Egypt was 26\% (Eladawi et al., 2014) [7] and considering a total population of (approximately 400 patients in 6 months attending family medicine outpatient clinic under an error $5 \%$, confidence interval level of 0.95 and at least $90 \%$ power for analysis. A minimal sample size of 148 participants was required to achieve the study objectives (per the Epi info 7), thus 148 participants were interviewed.

\section{Data collection tools and steps}

Informed written consent was taken from the participants after explaining the steps of the study. Then a structured questionnaire for patients was constructed to cover the following items:

- Socio-demographic data: including age, residency, education, occupation, and marital status

- History of duration and intensity of mastalgia, history of breast mass and nipple discharge, history of recent breast abscess, history of past breast illness, history of breast cancer, lactational history, and family history of breast pain or breast cancer

- Reproductive history: included menstrual history (age at first menstruation, regularity of menstruation, duration, amount, and premenstrual symptoms (PMS), obstetric history (number of pregnancies, age at first pregnancy), gynecological history (vaginal bleeding, vaginal discharge, pelvic pain) and contraceptive history (if she uses a contraception and which type)

- Weight, Height, and body mass index (BMI) was measured. Then full breast examination includes Breast mass (unilateral or bilateral, site, number, and size), nipple discharge, and lymph nodes examination

- $\quad$ Mastalgia was assessed by new breast pain score (BPS), which is a graph used to measure the pain score of the woman, in the context of a visual linear analog rating scale from 0 to 10 , the patient reports' pain severity regularly. The patient also reports pain score on a different section of the graph during her menstruation, which makes this graph more advantageous than other breast pain graphs as this enables us to imagine the severity of pain of the full month in an uncomplicated manner, with an objective calculation of the overall pain score over the entire month. It is feasible to sum the scores of a full month and compute its mean, median, standard deviation, or 95\% confidence interval. Hence, participants were asked to assess her pain by means of $10 \mathrm{~cm}$ visual analog scale (VAS) as mild (1-4 cm), intermediate (5-7), and severe $(8-10 \mathrm{~cm})$ and write the number in the chart that was given to her to assess pain. The patients were remembered weekly to record the score or any new symptom.

\section{Statistical analysis}

All data were collected and statistically analyzed using SPSS 26.0 for windows. Quantitative data were expressed as the mean \pm SD and median (range), and qualitative data were expressed as absolute frequencies (number) and relative frequencies (percentage). Percent of categorical variables were compared using Chi-square test or Fisher's exact test when appropriate. Person correlation coefficient was calculated to assess relationship between various study variables, (+) sign indicate direct correlation and $(-)$ sign indicate inverse correlation, also values near to 1 indicate strong correlation and values near 0 indicate weak correlation. Logistic regression was done to evaluate various risk factors for moderate to severe mastalgia.

All tests were two sided. $p<0.05$ was considered statistically significant (S), $p \geq 0.05$ was considered statistically insignificant (NS).

\section{Ethical approvals}

Ethical approval was obtained from the Family Medicine department counsel and from the Ethical committee at National cancer institute and finally from the Research Committee of Cairo University. Informed consents were obtained from all participants after explaining the objectives of the study.

\section{Results}

The mean age of patients was 32.6 and their mean BMI was 24.8. The majority of the cases were 
highly educated $48 \%$ and working $58.1 \%$ as showed in (Table 1).

Table 1: Demographic characteristics of the studied group $(n=148)$

\begin{tabular}{lll}
\hline Variables & Study group $(\mathrm{n}=148)$ & \\
\hline Age (years) & & \\
Mean \pm SD & $32.6 \pm 8$ & \\
$\quad$ Range & $18-51$ & \\
BMI $\left(\mathrm{kg} / \mathrm{m}^{2}\right)$ & & \\
$\quad$ Mean \pm SD & $24.8 \pm 3.7$ & \\
$\quad$ Range & $18-36$ & \\
\hline Variables & No & 9.5 \\
\hline Education & 14 & 42.6 \\
$\quad$ Not educated & 63 & 48 \\
Middle education & 71 & 58.1 \\
$\quad$ High education & & 41.9 \\
Occupation & 86 & 74.3 \\
$\quad$ Working & 62 & 25.7 \\
$\quad$ Not working & 110 & \\
Residency & 38 & 20.9 \\
$\quad$ Urban & & 71.6 \\
$\quad$ Rural & 31 & 3.4 \\
Marital status & 106 & 4.1 \\
$\quad$ Single & 5 & \\
$\quad$ Married & 6 & \\
$\quad$ Widow & & \\
$\quad$ Divorced & &
\end{tabular}

There was a positive family history of breast pain in $26.4 \%$ of the participants, most of the participants $66.9 \%$ breastfed their offspring. The mean age of menarche was $12 \pm 3$ and the duration of menstrual blood flow was more than 5 days in most of the cases $57.4 \%$. Breast pain was 5 days or less in $64.9 \%$ of the cases. The PMS symptoms have been founded in $56.1 \%$ of the participants (Table 2 ).

Table 2: Menstrual and contraceptive history of the studied group $(n=148)$

\begin{tabular}{|c|c|c|}
\hline Variables & \multicolumn{2}{|c|}{ Study group $(n=148)$} \\
\hline \multicolumn{3}{|c|}{ Age of menarche (years) } \\
\hline Mean \pm SD & \multicolumn{2}{|l|}{$12 \pm 3$} \\
\hline \multicolumn{3}{|l|}{ Range } \\
\hline Variables & $n$ & $\%$ \\
\hline \multicolumn{3}{|l|}{ Family history } \\
\hline Positive & 39 & 26.4 \\
\hline Negative & 109 & 73.6 \\
\hline \multicolumn{3}{|l|}{ Past history } \\
\hline Positive & 15 & 10.1 \\
\hline Negative & 133 & 89.9 \\
\hline \multicolumn{3}{|l|}{$\mathrm{N}$ of birth } \\
\hline$\leq 2$ & 99 & 66.9 \\
\hline$>2$ & 49 & 33.1 \\
\hline \multicolumn{3}{|l|}{ Breast feeding } \\
\hline Yes & 99 & 66.9 \\
\hline No & 49 & 33.1 \\
\hline \multicolumn{3}{|l|}{ Contraception } \\
\hline Not used & 69 & 46.6 \\
\hline Hormonal & 37 & 25.0 \\
\hline Non hormonal & 42 & 28.4 \\
\hline \multicolumn{3}{|c|}{ Hormonal medications } \\
\hline Yes & 6 & 4.1 \\
\hline No & 142 & 95.9 \\
\hline \multicolumn{3}{|c|}{ Menstrual regularity } \\
\hline Regular & 102 & 68.9 \\
\hline Irregular & 46 & 31.1 \\
\hline \multicolumn{3}{|l|}{ Menstrual duration } \\
\hline $3-5$ & 63 & 42.6 \\
\hline$>5$ & 85 & 57.4 \\
\hline \multicolumn{3}{|c|}{ Associated pelvic pain } \\
\hline Yes & 30 & 20.3 \\
\hline No & 118 & 79.7 \\
\hline \multicolumn{3}{|l|}{ Side of breast pain } \\
\hline Unilateral & 41 & 27.7 \\
\hline Bilateral & 107 & 72.3 \\
\hline \multicolumn{3}{|l|}{ Duration of pain } \\
\hline$\leq 5$ & 96 & 64.9 \\
\hline $6-10$ & 42 & 26.4 \\
\hline$>10$ & 10 & 6.8 \\
\hline \multicolumn{3}{|c|}{ Premenstrual tension symptoms } \\
\hline Yes & 83 & 56.1 \\
\hline No & 65 & 43.9 \\
\hline
\end{tabular}

The mean score of the new BPS of the studied participants was 4.67 ranging from (0 to 10$)$ with
$84(56.75 \%)$ of them having mild mastalgia with VAS score $\leq 4$, while $64(43.25 \%)$ have moderate to severe mastalgia with VAS $>4$ (Table 3 ).

Table 3: Comparing demographic, menstrual and contraceptive characteristics between the studied groups $(n=148)$

\begin{tabular}{|c|c|c|c|c|c|}
\hline \multirow{4}{*}{$\begin{array}{l}\text { Variables } \\
\text { Age (years): Mean } \pm \mathrm{SD} \\
\text { BMI }\left(\mathrm{kg} / \mathrm{m}^{2}\right): \text { Mean } \pm \mathrm{SD} \\
\text { Variables }\end{array}$} & \multicolumn{2}{|c|}{$\begin{array}{l}\text { Mild pain }(\mathrm{VAS} \leq 4) \\
(\mathrm{n}=84)\end{array}$} & \multicolumn{2}{|c|}{$\begin{array}{l}\text { Moderate to severe pain } \\
(\text { VAS }>4)(n=64)\end{array}$} & $p$-value \\
\hline & \multirow{2}{*}{\multicolumn{2}{|c|}{$\begin{array}{l}32.8 \pm 7.9 \\
22.7 \pm 2.5 \\
\end{array}$}} & \multirow{2}{*}{\multicolumn{2}{|c|}{$\begin{array}{l}32.4 \pm 8.2 \\
27.6 \pm 3.1\end{array}$}} & 0.746 \\
\hline & & & & & $<0.001^{* \star}$ \\
\hline & $\mathrm{n}$ & $\%$ & $\mathrm{n}$ & $\%$ & $p$-value \\
\hline \multicolumn{6}{|l|}{ Marital status } \\
\hline Single & 18 & 58.1 & 13 & 41.9 & \multirow[t]{4}{*}{0.841} \\
\hline Married & 60 & 56.6 & 46 & 43.4 & \\
\hline Widow & 2 & 40 & 3 & 60 & \\
\hline Divorced & 4 & 66.7 & 2 & 33.3 & \\
\hline \multicolumn{6}{|l|}{ Family history } \\
\hline Positive & 24 & 61.5 & 15 & 38.5 & \multirow[t]{2}{*}{0.842} \\
\hline Negative & 60 & 55 & 49 & 45 & \\
\hline \multicolumn{6}{|l|}{ Past history } \\
\hline Positive & 10 & 66.7 & 5 & 33.3 & \multirow[t]{2}{*}{0.414} \\
\hline Negative & 74 & 55.6 & 59 & 44.4 & \\
\hline \multicolumn{6}{|l|}{ Contraception } \\
\hline Not used & 43 & 62.3 & 26 & 37.7 & \multirow[t]{3}{*}{$<0.001^{\star \star}$} \\
\hline Hormonal & 4 & 10.8 & 33 & 89.2 & \\
\hline Non hormonal & 37 & 88.1 & 5 & 11.9 & \\
\hline \multicolumn{6}{|l|}{ Hormonal medications } \\
\hline Yes & 5 & 83.3 & 1 & 16.7 & \multirow[t]{2}{*}{0.180} \\
\hline No & 79 & 55.6 & 63 & 44.4 & \\
\hline \multicolumn{6}{|l|}{ Menstrual regularity } \\
\hline Regular & 64 & 62.7 & 38 & 37.3 & \multirow[t]{2}{*}{$0.029^{*}$} \\
\hline Irregular & 20 & 43.5 & 26 & 56.5 & \\
\hline \multicolumn{6}{|l|}{ Menstrual duration } \\
\hline $3-5$ & 53 & 84.1 & 10 & 15.9 & \multirow[t]{2}{*}{$<0.001^{* *}$} \\
\hline$>5$ & 31 & 36.5 & 54 & 63.5 & \\
\hline \multicolumn{6}{|l|}{ Associated pelvic pain } \\
\hline Yes & 15 & 50 & 15 & 50 & \multirow[t]{2}{*}{0.403} \\
\hline No & 69 & 58.5 & 49 & 41.5 & \\
\hline \multicolumn{6}{|l|}{ Side of breast pain } \\
\hline Unilateral & 26 & 63.4 & 15 & 36.6 & \multirow[t]{2}{*}{0.312} \\
\hline Bilateral & 58 & 54.2 & 49 & 45.8 & \\
\hline \multicolumn{6}{|l|}{ Duration of pain } \\
\hline$\leq 5$ & 73 & 76 & 23 & 24 & \multirow[t]{3}{*}{$<0.001^{* *}$} \\
\hline $6-10$ & 10 & 23.8 & 32 & 76.2 & \\
\hline$>10$ & 1 & 10 & 9 & 90 & \\
\hline $\begin{array}{l}\text { Premenstrual tension } \\
\text { symptoms }\end{array}$ & & & & & \\
\hline Yes & 27 & 32.5 & 56 & 67.5 & $<0.001^{* \star}$ \\
\hline No & 57 & 87.7 & 8 & 12.3 & \\
\hline
\end{tabular}

There was highly statistically significant difference between females with mild pain and those of moderate to severe pain regarding to $\mathrm{BMI}$ as the mean of $\mathrm{BMI}$ in patient with mild pain was $22.7 \pm 2.5$ while it was $27.6 \pm 3.1$ in females with moderate to severe pain (Table 3).

Furthermore, there was highly statistically significant difference between both groups as regards to the type of the contraception used that means females who used hormonal contraception had more pain (Table 3).

Sixty-two percent of females with mild pain have regular menstruation, while $56.5 \%$ of patients with moderate to severe pain have irregular menses. Females with longer menstrual blood flow were associated with moderate-to-severe pain than those with mild pain. Ninety percent of patients who have moderate-to-severe pain their breast pain duration more than 10 days. Most of the patients with PMS symptoms $67.5 \%$ were having moderate to severe pain (Table 3 ).

There was a strong positive association between BMI and average pain score with increasing the average of pain score with the high BMI (Table 4). After logistic regression, the only remaining significant factor was BMI 0.001 (Table 5). 
Table 4: Correlation between average pain score, age, and BMI

\begin{tabular}{lll}
\hline Items & Average pain score & \\
\cline { 2 - 3 } & $\mathrm{R}$ & $\mathrm{p}$ \\
\hline BMl & 0.693 & $<0.001^{\text {** }}$ \\
Age & -0.037 & 0.657 \\
\hline
\end{tabular}

BMI: Body mass index.

\section{Discussion}

In the current cross-sectional study, we study the factors affecting mastalgia in 148 patients. This study was conducted in family medicine clinics at kasralainy hospital and early detection and screening unit at national cancer institute.

Regarding the age in our study the mean age was $(32.6 \pm 8)$, the age was ranged from 18 to 51 , this was agreed with Johnson et al., 2006 [4] who stated that the age of women complaining of mastalgia was between 35 and 55 years, however the age in the study conducted in turkey by Mynit et al., 2016 [8] on 700 patients, the mean age of the participants was $(45.20 \pm 10.78)$ years (range 18-67). Commonly mastalgia affects about $60 \%$ of women aged 18-44 where most of it was cyclic.

Regarding BMI in our study, the mean BMI was (24.8 \pm 3.7 ) ranged from (18 to 36 ), while Olfati et al., 2009 [9] who study the relationship between BMI and mastalgia on 102 patients in Iran, stated that the mean BMI was $(28.81+3.22)$ and it concluded that patient with abnormal BMI had mastalgia than those with normal BMI.

Most of the patients in our study were married $71.6 \%$ and breastfed their children $66.9 \%$. This is in accordance with El Adwi et al., 2014 [7], that reported mastalgia was more frequent among married than single participants $(50.0 \%$ vs. $25.9 \%$; respectively). This might be due to pregnancy and breastfeeding. Breastfeeding may also be common cause of mastalgia in women, especially after labor. Furthermore, mastitis occurs more during breastfeeding and leads to mastalgia [10].

In this study, the highly educated patients $48 \%$ were more than the non-educated patients $9.5 \%$. also, Koçoğlu et al., 2017 [11] found the fact that women who graduated from university suffered from mastalgia more frequently.

Patients who lived in urban areas in this study were the majority $74.3 \%$, more than half of the patients were working $58 \%$. This can be explained by a psychogenic origin of breast pain. Women highly educated were working, and lived in urban areas might have more stressors. Stressors can be the cause of psychogenic health problems in women [12].

The majority of participants in this study were complaining of mild pain (VAS $\leq 4$ ) $56.7 \%$ while those with moderate-to-severe pain (VAS> 4) were $43.2 \%$ with the mean pain score was 4.67.

This was not agreed with Myint et al., 2016 [8] who reported that $41 \%$ of the participants who had mild mastalgia. However, the mean pain score was similar to Ader and Brown's study [13] (Mean=4.63 \pm 2.3 ).

In our study, in most participants (64.9\%) duration of mastalgia was 5 days or less, this was consistent with Varizi et al., 2016 [5] who stated that the duration of pain in $65 \%$ of participants was 5 days or less. However, in Carmichael and colleagues' study [14] $93 \%$ of the participants reported more than 5 days of mastalgia.

In the current study, most patients had reported bilateral mastalgia $72.3 \%$, this was in line with Varizi et al., 2016 [5] as most mastalgic participants had bilateral breast pain $64 \%$.

The major findings of the current study were that mastalgia is statistically significant related to BMI, type of contraception, menstrual regularity, menstrual duration, breast pain duration, and PMS.

There was highly statistically significant difference between patient with mild pain and those of moderate to severe pain regarding to BMI as patient with moderate to severe pain have higher BMI. This was consistent to the study in India by Raghunath et al., 2015 [15] showed that Women who had low BMI had higher risk for mastalgia as compared to those with normal BMI. Johnson et al., 2006 [4] identified the obesity as a risk factor in their study.

As regards the type of the contraception used this study demonstrated that the use of hormonal contraception associated with more pain $(p<0.001)$, this is not agreed with Shobeiri et al., 2016 [16] who resulted that Hormonal contraceptive usage was associated with significantly less mastalgia.

In this study mastalgia significantly related to menstrual regularity and duration with $p=0.029,0.001$ respectively, this is not in line with Varizi et al., 2016 [5] who demonstrated that mastalgia not related to them as the $p$ value was $0.698,0.607$ respectively.

Table 5: Logistic regression of the associated risk factors of increased pain

\begin{tabular}{|c|c|c|c|c|c|c|c|c|}
\hline \multirow[t]{2}{*}{ Items } & \multirow[t]{2}{*}{ B } & \multirow[t]{2}{*}{ S.E. } & \multirow[t]{2}{*}{ Wald } & \multirow[t]{2}{*}{ df } & \multirow[t]{2}{*}{ Sig. } & \multirow{2}{*}{$\begin{array}{l}\operatorname{EXP}(B) \\
\text { OR }\end{array}$} & \multicolumn{2}{|c|}{$95 \% \mathrm{Cl}$ for $\operatorname{EXP}(\mathrm{B})$} \\
\hline & & & & & & & Lower & Upper \\
\hline Type of contraception & -0.428 & 0.288 & 2.202 & 1 & 0.138 & 0.652 & 0.371 & 1.147 \\
\hline Regular menses & -0.284 & 0.528 & 0.289 & 1 & 0.591 & 0.753 & 0.267 & 2.121 \\
\hline Menstrual duration 3-5.1, >5.2 & 0.268 & 0.563 & 0.227 & 1 & 0.634 & 1.307 & 0.434 & 3.940 \\
\hline Duration of pain in menstrual cycle & -0.034 & 0.555 & 0.004 & 1 & 0.951 & 0.967 & 0.326 & 2.869 \\
\hline PMS & -0.662 & 0.607 & 1.192 & 1 & 0.275 & 0.516 & 0.157 & 1.693 \\
\hline BMI & 0.524 & 0.158 & 10.951 & 1 & $0.001^{*}$ & 1.689 & 1.238 & 2.303 \\
\hline
\end{tabular}


Our study showed there was mastalgia related to PMS as patient with PMS had more pain $(p<0.001)$, this was inconsistent with Shobeiri et al., 2016 [16] Also, they also reported in another observation that mastalgia was not significantly associated with PMS.

\section{Conclusion}

We concluded that there are many factors affecting mastalgia as BMI, type of contraception, menstrual regularity, menstrual duration, breast pain duration, and PMS. However, BMI is the most important factor affecting mastalgia, so in the prevention of mastalgia, it can be concluded that BMI within the normal range can be significant. In addition, weight loss may have a therapeutic effect if women suffering from breast pain are also having weight issues.

Our study had some limitations. We did not select the participants via a randomized method. Furthermore, we did not identify the dietary regimens of the participants. Hence, the relationship between mastalgia and dietary habits remained unclear.

\section{References}

1. Eren T, Aslan A, Ozemir IA, Baysal H, Sagiroglu J, Ekinci O, et al. Factors effecting mastalgia. Breast Care (Basel, Switzerland). 2016;11(3):188-93. https://doi.org/10.1159/000444359 PMid:27493619

2. Grullon S, Bechmann S. Mastodynia. In: StatPearls. Treasure Island, FL: StatPearls Publishing; 2020. Available from: https:// www.ncbi.nlm.nih.gov/books/NBK559249 [Last accessed on 2020 Jun 22].

3. Mohammed AA. Evaluation of mastalgia in patients presented to the breast clinic in Duhok city: cross sectional study. Ann Med Surg. 2020;52:31-5. https://doi.org/10.1016/j.amsu.2020.02.012 PMid:32194960

4. Johnson KM, Bradley KA, Bush K, Gardella C, Dobie DJ, Laya $\mathrm{MB}$, et al. Frequency of mastalgia among women veterans: Association with psychiatric conditions and unexplained pain syndromes. J Gen Internal Med. 2006;21(3):S70-5. https://doi. org/10.1111/j.1525-1497.2006.00378.x.

PMid:16637950

5. Vaziri F, Samsami A, Rahimi Z, Rastgardoost N, Nick N. Prevalence, severity and factors related to mastalgia among women referring to health centers affiliated with Shiraz University of medical sciences. J Health Sci Surveill Syst. 2016;4(2):64-9.

6. Yıldırım AC, Yıldız P, Yıldız M, Kahramanca S, Kargıcı H Mastalgia-cancer relationship: A prospective study. J Breast Health. 2015;11(2):88. https://doi.org/10.5152/tjbh.2015.2492 PMid:28331698

7. Eladawi N, Abdel-Hady D, El-Gilany AH, Gibreel A. Mısır'da mansoura üniversitesi kadin tip öğrencilerinde mastalji. TAF Prev Med Bull. 2014;13(4):307-14.

8. Thu M, Diaz EO. Premenstrual syndrome among female University students in Thailand faculty of nursing science. Thailand AU J T. 2006;9(3):158-62.

9. Olfati $F$, Kazemi JH, Farhad $M$. Survey the relationship between BMI and cyclic Mastalgia. J Guilan Univ Med Sci Win. 2009;17(68):50-56.

10. Shriver CD, Ader DN. Cyclical mastalgia: Prevalence and impact in an outpatient breast clinic sampl. J Am Coll Surg. 1997;185(5):466-70. https://doi.org/10.1016/ s1072-7515(97)00095-1

PMid:9358091

11. Koçoğlu D, Kurşun S, Akın B, Altuntug K. Mastalgia and associated factors: A cross-sectional study. Agri. 2017;29(3):1008. https://doi.org/10.5505/agri.2017.91069 PMid:29039149

12. Colegrave S, Holcombe C, Salmon P. Psychological characteristics of women presenting with breast pain. J Psychosom Res. 2001;50(6):303-7. https://doi.org/10.1016/ s0022-3999(01)00196-9 PMid:11438111

13. Ader DN, Browne MW. Prevalence and impact of cyclic mastalgia in a United States clinic-based sample. Am J Obstet Gynecol. 1997;177(1):126-32. https://doi.org/10.1016/ s0002-9378(97)70450-2 PMid:9240595

14. Carmichael AR, Bashayan O, Nightingale P. Objective analyses of mastalgia in breast clinics: Is breast pain questionaire a useful tool in a busy breast clinic? 2006;15(4):498-502. https:// doi.org/10.1016/j.breast.2005.10.009

PMid:16337794

15. Raghunath S, Raghuram N, Ravi S, Ram NC, Ram A Prevalence of mastalgia in young Indian females. $\mathrm{J}$ Health Res Rev. 2015;2(3):108:

16. Shobeiri F, Oshvandi K, Nazari M. Cyclical mastalgia: Prevalence and associated determinants in Hamadan city, Iran. Asian Pac J Trop Biomed. 2016;6(3):275-8. 